
University of Crete, Greece

\author{
Panos Bitsios, ${ }^{1}$ Evangelos Karademas, ${ }^{2}$ Angeliki Mouzaki, ${ }^{3}$ George \\ Manolitsis, ${ }^{4}$ Ourania Kapellaki, ${ }^{5}$ Anastasia Diacatou, ${ }^{6}$ Arianna Archontaki, \\ George Mamalakis ${ }^{8}$ and Theodoros Giovazolias ${ }^{9}$
}

'Professor of Psychiatry, Medical School, University of Crete, Greece, email bitsiosp@uoc.gr

2Professor of Clinical Health Psychology, Department of Psychology, University of Crete, Greece

${ }^{3}$ Assistant Professor of Learning Disabilities, Department of Primary Education, University of Crete, Greece

${ }^{4}$ Associate Professor of Psychopedagogy, Department of Preschool Education, University of Crete, Greece

${ }^{5}$ Psychologist, Student Counselling Centre, University of Crete, Greece

${ }^{6}$ Psychologist, Student Counselling Centre, University of Crete, Greece

${ }^{7}$ Special Education Counsellor, Student Counselling Centre, University of Crete, Greece ${ }^{8}$ Psychologist, Student Counselling Centre, University of Crete, Greece

${ }^{9}$ Associate Professor of Counselling Psychology, Department of Psychology, Department of Psychology,
University of Crete, Greece
This report describes the Student Counselling Centre (SCC) at the University of Crete. The SCS was established in 2003. Its main areas of activity are individual and group psychological support, crisis intervention, research, prevention, volunteering and awareness. Emphasis is also put on the support provided to students with special needs, which is now the second core service of the SCC.

Worldwide, student populations have a higher prevalence and greater severity of mental health disorders (Rückert, 2015), commonly depression and anxiety (Kress et al, 2015). University-based counselling services have been established in response (for a review, see Prince, 2015). Standard practice is for such services to include: individual and group counselling; prevention and outreach; consultation for faculty and staff; and campus safety review (Holm-Hadullaa \& KoutsoukouArgyraki, 2015). Since the early 1990s, Greek universities have progressively become aware of the need for student psychological counselling as a means to prevent both academic and personal difficulties. The first student counselling centre (SCC) was founded at the University of Athens in 1990, by Professor Anastasia Kalantzi-Azizi.

The SCCs in Greece adhere to the current international standards and operate with the primary mission of helping students with emerging personal and educational difficulties (Giovazolias et al, 2010). The University of Crete established its SCC in 2003. It operates at two sites, Heraklion and Rethymno. The Heraklion site has two full-time psychologists providing counselling and a third member of staff who supports students with special needs at both sites. The Rethymno site operates with only one part-time psychologist and one volunteer psychologist offering 3 hours per week. At Heraklion one volunteer psychologist provides cognitive-behavioural therapy (CBT) and one volunteer psychologist provides group therapy (both recruited in 2016 to support the growing needs of the student population).

The SCC staff participate in continuous education activities such as seminars and conferences and receive clinical psychiatric input and supervision from the head of the SCC, who is an academic psychiatrist from the Medical School of the University, and weekly supervision from an experienced external psychotherapist. The SCC is run by a five-member executive committee. All members are academics at the University of Crete. The committee convenes twice a year to review administrative and general operational issues, and elects the head of the SCC every 2 years.

The SCC provides two core services: individual and group psychological support; and support of students with special needs.

\section{Individual and group psychological support}

This core service is provided for students who present with acute and transient conditions and common mental health problems such as examination anxiety, adjustment and mood disorders, or ongoing problems from interpersonal and personality difficulties, and issues relating to gender identity and sexual orientation. Students are either self-referred or referred by their peers or academic teachers. A total of 1097 undergraduate and postgraduate students were referred from 2003 to 2016 and given an average of 12 sessions per student, amounting to over 12000 total student contacts. After a slow start, the referral trends have shown a rapid increase since 2010, with more serious mental health problems being referred, probably reflecting a multitude of factors such as better awareness about the SCC among the academic community, transformation of students' attitudes (Vogel et al, 2007), the higher number of students entering the University year after year and possibly the non-specific effects of the Greek financial crisis on students' mental health (Kounenou et al, 2011). It must be emphasised that this number probably underestimates the true student need, since the SCC at the Rethymno site was closed between 2007 and 2011, and both sites are understaffed. There is currently a 20 -student waiting-list at each SCC site.

\section{Early intervention}

The SCC provides psychiatric diagnosis, risk assessment and early psychological and/or pharmacological intervention to students who can be treated safely in the community. The staff liaise with the local psychiatric services to refer more complex cases or high-risk students with mental illness as well as those in need of complex pharmacological treatment.

\section{Crisis resolution}

In collaboration with University authorities and the local mental health services, the SCC has managed 
13 crises arising from social or other conflict generated by students with acute and serious mental illness who required compulsory admission under the Greek Mental Health Act.

\section{Prevention and awareness}

The SCC has issued and published a large number of illustrated information leaflets on adaptation to university life, the difficulties with study and examinations, and information on several mental health problems.

The SCC has made a considerable contribution to increasing awareness of the general student population through printed material, induction courses and online social media. Faculty meetings have been organised in most departments to present strategies for assisting students in coping with academic demands and to address specific concerns. Similar actions have led to the activation of the role of academic tutors in all departments. These tutors can liaise with SCC staff when required, a practice suggested by many scholars in the field (e.g. Holm-Hadullaa \& KoutsoukouArgyraki, 2015).

The SCC has participated in preventive action targeting the wider community, such as educational events and seminars with secondary school teachers on mental health issues, and seminars for the prevention of substance misuse and addictions in liaison with the local/national substance misuse services and non-profit organisations. The SCC has also produced a number of CDs with information on relaxation techniques.

\section{Volunteeriing}

The SCC initiated a peer-support telephone line, whereby supervised trainee psychology graduate students provide support to fellow students in crisis (Skaniakos et al, 2014). The SCC encourages students to become active citizens of the local and wider society by encouraging the formation of volunteer groups. In this context, in liaison with social and welfare services that look after vulnerable children and adolescents in Heraklion, the SCC encourages students to offer their time, help and support. Students' interest was always very high and 312 volunteer students participated in this scheme in Heraklion alone. This initiative received an award from the Ministry of Justice.

\section{Assessment of students' needs}

In 2005 the SCC participated in national epidemiological research on student mental health, and in 2012 in a programme for smoking cessation in the student population.

\section{Collaboration with other SCCs and services}

The SCC communicates with similar services at other Greek universities in order to achieve both continuous improvement in and dissemination of its services. The SCC is a member of the European Association FEDORA-Psyche (Psychological Counselling in Higher Education). In September 2007, the University of Crete hosted the
FEDORA-Psyche conference 'Crossing Internal and External Borders: Practices for Effective Psychological Counselling in European Higher Education' (Giovazolias et al, 2008).

\section{Support of students with special needs}

This second core service of the SCC started in March 2007. It has become the University's 'single point of access' for any students to report their individual special educational needs and discuss the reasonable adjustments required to address them. The SCC then provides consultation to the deaneries and departmental secretarial offices. These students include those with specific learning disabilities (e.g. dyslexia), those with adult attention-deficit hyperactivity disorder, those who already have or who acquire during their studies a permanent or transient serious physical or mental condition that interferes with their class attendance and education, as well as students who suffer from very serious conditions and who have entered university without sitting examinations (5\% of all student entries).

Support of students with special needs entails confidential interviews with them for personalised assessment of their needs and skills, which results in a personalised intervention plan. In line with international standards (Oertle \& Bragg, 2014), intervention plans cover access to teaching and examination areas, alterations in the format, time, duration and place of teaching and examinations, use of digital technology for lectures and examinations, the provision of Braille books for the blind, allocation of 'shadowing' students who act as 'studies facilitators', and finally psychological support, if required.

\section{Conclusion}

Educational attainment is an important phenotype which together with cognitive function is linked aetiologically to mental illness, given that educational failure is a core characteristic of serious mental illness. Indeed, there is evidence for a genetic overlap between educational attainment, cognitive ability and risk of schizophrenia (Lencz et al, 2014; Trampush et al, 2015). Also, given the well-established relationship between educational attainment and cognition and general physical and psychological well-being (Deary, 2008; Johnson et al, 2009), and even longevity (Batty et al, 2008), improving educational attainment is potentially critical to improving physical and mental health outcomes. Three-quarters of all mental illnesses have an onset before the age of 25 and the age window of 16-25 is critical. Therefore, SCCs are ideally located to capture early psychopathology, and to prevent its chronic course and its detrimental impact on educational attainment and by extension on public health. The SCC has created an electronic database of help-seeking students with the intention of exploring risk factors for failure in educational attainment and psychopathology as well as resilience factors and the role of our biopsychosocial therapeutic interventions. 


\section{References}

Batty, G. D., Shipley, M. J., Gale, C. R., et al (2008) Does IQ predict total and cardiovascular disease mortality as strongly as other risk factors? Comparison of effect estimates using the Vietnam Experience Study. Heart, 94, 1541-1544.

Deary, I. J. (2008) Why do intelligent people live longer? Nature 456, 175-176.

Giovazolias, T., Karademas, E. C. \& Kalantzi-Azizi, A. (eds) (2008) Crossing Internal and External Borders: Practices for Effective Psychological Counselling in European Higher Education. Ellinika Grammata \& FEDORA-PSYCHE.

Giovazolias, T., Leontopoulou, S. \& Triliva, S. (2010) Assessment of Greek university students' counselling needs and attitudes: an exploratory study. International Journal for the Advancement of Counselling, 32, 101-116.

Holm-Hadullaa, R. M. \& Koutsoukou-Argyraki, A. (2015) Mental health of students in a globalized world: prevalence of complaints and disorders, methods and effectivity of counselling, structure of mental health services for students. Mental Health and Prevention, $3,1-4$

Johnson, W., Deary, I. J. \& Iacono, W. G. (2009) Genetic and environmental transactions underlying educational attainment. Intelligence, 37, 466-478.

Kounenou, K., Koutra, A., Katsiadrami, A., et al (2011)

Epidemiological study of Greek university students' mental health. Journal of College Student Development, 52, 475-486.
Kress, V., Sperth, M., Hofmann, F. H., et al (2015) Psychological complaints and disorders of students: a comparison of field samples with clients of a counseling service at a typical German university. Mental Health and Prevention, 3, 41-47.

Lencz, T., Knowles, E., Davies, G., et al (2014) Molecular genetic evidence for overlap between general cognitive ability and risk for schizophrenia: a report from the Cognitive Genomics consorTium (COGENT). Molecular Psychiatry, 19, 168-174.

Oertle, K. M. \& Bragg, D. D. (2014) Transitioning students with disabilities: community college policies and practices. Journal of Disability Policy Studies, 25, 59-67.

Prince, J. (2015) University student counselling and mental health in the United States: trends and challenges. Mental Health and Prevention, 3, 5-10.

Rückert, H. W. (2015) Mental health of students and psychological counseling in Europe. Mental Health and Prevention, 3, 34-40.

Skaniakos, T., Penttinen, L. \& Lairio, M. (2014) Peer group mentoring programmes in Finnish higher education - mentors' perspectives. Mentoring and Tutoring: Partnership in Learning, 22 $74-86$

Trampush, J. W., Lencz, T., Knowles, E., et al (2015) Independent evidence for an association between general cognitive ability and a genetic locus for educational attainment. American Journal of Medical Genetics Part B: Neuropsychiatric Genetics, 168, 363-373.

Vogel, D. L., Wade, N. G. \& Hackler, A. H. (2007) The mediating role of self-stigma associated with seeking help on intentions to seek counseling. Journal of Counseling Psychology, 54, 40-50.

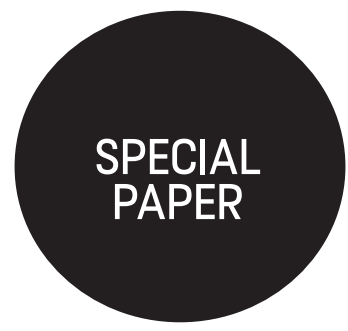

\title{
Developing substance misuse services in United Arab Emirates: the National Rehabilitation Centre experience
}

\author{
Hamad A. Al Ghaferi, ${ }^{1}$ Ahmed Y. Ali, ${ }^{1}$ Tarek A. Gawad ${ }^{1}$ and \\ Shamil Wanigaratne ${ }^{2}$
}

'National Rehabilitation Centre Abu Dhabi

${ }^{2}$ National Rehabilitation Centre, Abu Dhabi; United Arab Emirates University; King's College London, UK, email shamil.wanigaratne@ kcl.ac.uk
In 2001 a directive was issued to establish the National Rehabilitation Centre (NRC) to deal with the growing problem of substance misuse in the United Arab Emirates. The NRC has achieved many goals as a treatment and rehabilitation facility as well as a drug and alcohol demand reduction response centre. It is now working towards being an international centre of excellence.

Since its birth in 1971, the United Arab Emirates (UAE) has enjoyed an unparalleled transformation in every sphere of life. The transition from poverty to affluence over such a brief period has brought challenges to the indigenous population and required significant psychological adjustment (Al Nahyan, 2014). In addition to Westernisation and globalisation, the influx of a massive multinational workforce has had a significant impact on Emirati culture, traditions, and social and family structures.

Substance misuse in the UAE was not seen as a problem until the 1980 s, when increases in both the number of drug users and the amounts used were observed. Drug use had spread from a few isolated examples in some ethnic groups to many, including Emiratis (Sarhan, 1995). UAE citizens now account for less than $20 \%$ of the total population. The observation that drug misuse is spreading faster among this sector than among other nationalities makes it both a cause for concern and a national security issue. An indirect indication of the substance misuse problem comes from a study of suicides in Dubai between 1992 and 2000, which showed an annual rate of suicide of 6.2/100000. Of this figure, $27 \%$ tested positive for alcohol, with no significant difference between Muslims and non-Muslims (Koronfel, 2002).

A recent qualitative study carried out by the National Rehabilitation Centre (NRC) on 13- to 18-year-old adolescents showed that there were notable gender and age differences in knowledge of and attitudes to substance misuse. For example, 17- to 18-year-old males were able to name different alcoholic beverages, street names of drugs and routes of administration. Females noted that substance misuse was more permissible for males 